\title{
A PSICANÁliSE E O DIREITO AO ESQUECIMENTO
}

\section{THE PSICHOANALYSIS AND THE RIGHT TO OBLIVION}

\section{Juarez Sanfelice Dias}

Mestre em Direito Tributário pela PUC/SP, Doutorando em Filosofia do Direito pela PUC/SP, Procurador do Estado de São Paulo e Professor do Curso de Direito da PUC/Campinas.

\section{RESUMO:}

O presente artigo busca contribuições da psicanálise para o tema do direito ao esquecimento. Este pode ser definido como o direito de uma pessoa impedir a divulgação de fatos desabonadores ocorridos ao longo de sua vida, tendo como embasamento a ocorrência de um lapso temporal e a mudança de comportamento.

\section{Palavras-chave:}

Direito ao esquecimento, psicanálise, liberdade de comunicação, dignidade da pessoa humana.

\section{ABSTRACT:}

This article seeks contributions of psychoanalysis to the theme of the right to oblivion. This can be defined as the right of a person to prevent the disclosure of discreditable events that occurred throughout his life, having as background the occurrence of a time gap and changes in behavior.

\section{Key words:}

Right to oblivion, psychoanalysis freedom of communication, human dignity.

\section{SUMÁRIO:}

Introdução. 1. Freud, o totem e o tabu. 2. Jung e o inconsciente coletivo. 3. Freud, Lacan, a primazia do inconsciente, recalque e esquecimento. Conclusões. Referências bibliográficas. 


\section{Introdução}

O presente artigo objetiva trazer contribuições da psicanálise para o tema do direito ao esquecimento. Este pode ser definido como a tutela da intimidade privada com vistas a impedir a divulgação de fatos desabonadores ocorrido durante a vida de uma pessoa.

O direito ao esquecimento ganhou destaque especialmente após o caso Lebach, ocorrido na Alemanha. O nome deve-se à cidade alemã onde ocorreu um crime bárbaro que redundou na condenação de três pessoas, duas à prisão perpétua e um terceiro à pena de seis anos de reclusão. Às vésperas de sair da prisão, a televisão alemã elaborou documentário retratando o crime, inclusive com a citação inicial dos nomes dos verdadeiros envolvidos no crime.

O condenado, tendo cumprido a pena fixada pelo ordenamento jurídico, pretendia a volta à convivência com a ressocialização. A divulgação de seu nome e do crime ocorrido contemporaneamente à sua saída da prisão era um evidente obstáculo às pretensões do recém liberto.

Ingressou perante o Tribunal alemão objetivando impedir a divulgação dos fatos, invocando assim um pretenso direito a ser esquecido, de não ser novamente lembrado.

Haveria embasamento para este direito de ser esquecido, de ser deixado em paz, de não mais ser lembrado?

Nos dias atuais o esquecimento ganhou outros contornos, sendo utilizado por vítimas ou parentes de vítimas para impedir a divulgação dos crimes, evitando assim reviver o sofrimento pretérito. 
Da mesma forma, diante das novas tecnologias, rede mundial de computadores, que torna a divulgação de informações mais rápida e sem fronteiras, o tema tem tomado proporções mundiais, ultrapassando as fronteiras estatais, especialmente com relação à possibilidade e efetividade de aplicação deste direito, ainda que reconhecido.

No direito pátrio a discussão gira em torno do conflito existente entre valores previstos na Carta de 1988 que fixam os contornos da liberdade de imprensa, de um lado, e da proteção à intimidade e à vida privada, de outro. A disciplina está prevista nos artigos $5^{\circ}$ e 220 da Constituição Federal:

"Art. 5 $5^{\circ}$ Todos são iguais perante a lei, sem distinção de qualquer natureza, garantindo-se aos brasileiros e aos estrangeiros residentes no País a inviolabilidade do direito à vida, à liberdade, à igualdade, à segurança e à propriedade, nos termos seguintes:

IV - é livre a manifestação do pensamento, sendo vedado o anonimato;

V - é assegurado o direito de resposta, proporcional ao agravo, além da indenização por dano material, moral ou à imagem; ...

IX - é livre a expressão da atividade intelectual, artística, científica e de comunicação, independentemente de censura ou licença;

X - são invioláveis a intimidade, a vida privada, a honra e a imagem das pessoas, assegurado o direito a indenização pelo dano material ou moral decorrente de sua violação;

XIII - é livre o exercício de qualquer trabalho, ofício ou profissão, atendidas as qualificações profissionais que a lei estabelecer;

XIV - é assegurado a todos o acesso à informação e resguardado o sigilo da fonte, quando necessário ao exercício profissional;" 
"Art. 220. A manifestação do pensamento, a criação, a expressão e a informação, sob qualquer forma, processo ou veículo não sofrerão qualquer restrição, observado o disposto nesta Constituição.

$\S 1^{\circ}$ Nenhuma lei conterá dispositivo que possa constituir embaraço à plena liberdade de informação jornalística em qualquer veículo de comunicação social, observado o disposto no art. 5 IV, V, X, XIII e XIV."

A existência de princípios constitucionais a prestigiar o direito à liberdade de informação, à liberdade de imprensa e também a dignidade da pessoa humana, sua intimidade e vida privada, sua honra e imagem, sem critérios objetivos para a solução de eventuais conflitos leva-nos ao socorro à psicanálise, justamente em busca de argumentos que poderão ser utilizados pelo Poder Judiciário diante dos casos práticos levados à sua apreciação.

\section{Freud, o totem e o tabu}

O registro dos fatos e sua lembrança é comum ao direito e à psicanálise. O direito ao esquecimento lida com este tema, que é inerente ao ser-humano desde sempre.

Passado e presente, memória e esquecimento, desejo e repulsa. As dualidades estão presentes na vida.

Dois temas importantes abordados pela psicanálise são o tabu e totem, exaustivamente estudados por FREUD. Tabu e totem sempre existiram na civilização. São comportamentos aparentemente sem origem conhecida e sem uma explicação científica ou lógica.

Conforme leciona Freud, “o significado de 'tabu’ se divide, para nós, em duas direções opostas... por um lado que dizer 'santo, consagrado'; por outro, 'inquietante, perigoso, proibido, impuro. O contrário de 'tabu' em polinésio, é noa, ou seja, 'habitual, acessível a todos"”. Assim, continua, “tabu 
está ligado à ideia de algo reservado, exprime-se em proibições e restrições, essencialmente”. (Freud, 2015, p. 12)

Freud pontifica que as proibições do tabu sempre existiram na humanidade e remontam a épocas longínquas, nos primórdios das civilizações, não tendo origem conhecida:

"As proibições do tabu prescindem de qualquer fundamentação; têm origem desconhecida; para nós obscuras, parecem evidentes para aqueles sob o seu domínio... é o mais antigo código de leis não escritas da humanidade... remontando a épocas anteriores a qualquer religião". (p. 12-13)

Se uma determinada pessoa violasse um tabu, se tornaria ela mesma um tabu, carreando para si esta pecha, esta verdadeira maldição:

A violação de um tabu torna tabu o próprio infrator. Alguns dos perigos trazidos pela violação podem ser conjurados por atos de penitência e purificação" (p. 14)

Já o totem, "via de regra é um animal, comestível, inofensivo ou perigoso, temido, e mais raramente uma planta ou força da natureza (chuva, água), que tem uma relação especial com todo o clã.” (p. 8)

O autor ensina que "os membros do clã não podem comer ou tocar no totem, sob pena de se tornarem, eles, um totem, se tornando impuros... não podem os membros do mesmo clã ter relações sexuais entre si, nem se casar. (p. 10) 
As figuras do totem e do tabu demonstram que desde épocas remotas, tempos imemoriais o ser-humano trabalha com fatos ou circunstâncias proibidas e de origem desconhecidas, sendo estas proibições não fundamentadas, aparentemente não conscientes, fruto de meras crendices ou mesmo oriundas do inconsciente.

Com apoio em Wilhelm Wundt, Freud pontifica que o tabu pode ter por objeto o próprio homem, um animal ou um objeto. Todas as formas têm origem no temor à ação demoníaca (Freud, p. 18). Aos poucos, no entanto, o tabu acaba por se fundamentar em si mesmo, ganhando uma independência.

Duas leis fundamentais do totemismo, ou seja, "não liquidar o animal totêmico e evitar relações sexuais com os indivíduos do mesmo totem que são do sexo oposto" são, coincidentemente as mais antigas proibições do tabu. (Freud, p. 27)

Freud faz uma ligação interessante entre as figuras do tabu, do totem e a conduta do neurótico. Tabu e totem são proibições, renúncias de algo que se desejaria. É a luta do desejado com o proibido, do consciente e do inconsciente:

"O tabu é uma proibição antiquíssima, imposta do exterior (por uma autoridade) e voltada contra os mais fortes desejos do ser humano. A vontade de transgredi-lo continua a existir no inconsciente; aqueles que obedecem ao tabu têm uma postura ambivalente quanto ao alvo do tabu. A força mágica a ele atribuída remonta à capacidade de induzir em tentação; ela age como um contágio, porque o exemplo é contagioso, e porque o desejo proibido deslocase para outra coisa no inconsciente. Expiar a violação do tabu com uma renúncia mostra que na base da obediência ao tabu se acha uma renúncia." (Freud, 2015, p. 30)

Clara a pertinência do texto mencionado com o direito, especialmente nos conceitos de imposição, proibição, eficácia e transgressão da norma e sua efetividade, reclamando sua execução a título 
educativo. A norma não pode ser descumprida, sob pena de se tornar uma norma sem efetividade, uma norma "que não pegou".

Inegável a ligação destas figuras com a temática do direito ao esquecimento. Totem e tabu dão base a comportamentos sem uma fundamentação racional, cuja origem é desconhecida e não pode ser questionada. No direito ao esquecimento, assim como no totemismo e no tabu, também se verifica um conflito, agora no campo do direito, deste debate interno que sempre permeou a existência do homem. Pode o direito determinar o esquecimento? Esta determinação é dotada de eficácia? Mesmo o direito determinando o esquecimento, a não divulgação, é esta determinação eficaz em seu intento? São questões eternas do homem e que ficam suspensas, sem uma resposta definitiva. Mas, prossigamos em nossa pesquisa, agora abordando outro autor.

\section{Jung e o inconsciente coletivo}

Outro psicanalista que pode nos auxiliar nesta pesquisa é Jung. Pontifica este autor que o primeiro conceito trazido pela psicanálise é o de inconsciente, que pode ser definido como "o estado dos conteúdos reprimidos ou esquecidos”. (Jung, 2014, p.11)

Em Freud o inconsciente adquire inicialmente este conteúdo pessoal. Jung o denomina inconsciente pessoal, querendo se referir à "camada mais ou menos superficial do inconsciente”, ... cujos conteúdos "são principalmente os complexos de tonalidade emocional, que constituem a intimidade pessoal da vida anímica." (Jung, 2014, p. 12)

Jung trabalha com uma forma de inconsciente a que denomina de coletivo, que "repousa sobre uma camada mais profunda, que já não tem sua origem em experiências ou aquisições pessoais, sendo inata, ...., que possui conteúdos e modos de comportamento, os quais são cum grano salis os mesmos em toda parte e em todos os indivíduos." (Jung, p. 12) 
Leciona, a seguir, que "enquanto o inconsciente pessoal é constituído essencialmente de conteúdos que já foram conscientes e, no entanto, desapareceram da consciência por terem sido esquecidos ou reprimidos, os conteúdos do inconsciente coletivo nunca estiveram na consciência e, portanto, não foram adquiridos individualmente, mas devem sua existência apenas à hereditariedade.” (Jung, p. 51)

Aos conteúdos deste inconsciente coletivo o autor denomina arquétipos. Os arquétipos são "tipos arcaicos, primordiais, isto é, ... imagens universais que existiram desde os tempos mais remotos.” (p. 13)

Ele sustenta existir boas razões para ligar os arquétipos a imagens inconscientes dos próprios instintos, dos comportamentos instintivos. (p. 53)

Uma importante diferença entre o inconsciente individual e o coletivo é que este último é constituído por arquétipos e aquele é constituído por complexos, fruto de experiências pessoais reprimidas.

Três arquétipos importantes são citados, a "sombra", a "anima" e o "velho sábio". A existência de um inconsciente coletivo pode ser demonstrada através (1) dos sonhos, (2) da imaginação ativa e (3) dos delírios dos doentes mentais. A fonte principal de demonstração está nos sonhos, que são manifestações isentas e não controladas pelo lado consciente da psique. (p.57)

Os ensinamentos tribais, esotéricos, os mitos e os contos de fadas são exemplos de arquétipos que foram submetidos à elaboração consciente. Não entram, segundo relata, ao conceito de arquétipos em virtude desta materialização e incorporação à tradição social. Os mitos são antes de mais nada manifestações internas, da alma, fato este constantemente negado pelos estudiosos da mitologia, que sempre buscaram uma resposta na natureza: 
"Ele simplesmente ignorava que a alma contém todas as imagens das quais surgiram os mitos, e que nosso inconsciente é um sujeito atuante e padecente, cujo drama o homem primitivo encontra analogicamente em todos os fenômenos grandes e pequenos da natureza." (Jung, p. 15)

“ O inconsciente é considerado geralmente como uma espécie de intimidade pessoal encapsulada, ... este é o modo como o inconsciente é visto pelo lado consciente. A consciência, porém, parece ser essencialmente uma questão de cérebro, o qual vê tudo, separa e vê isoladamente, inclusive o inconsciente, encarado sempre como meu inconsciente. Pensa-se por isso de um modo geral que quem desce ao inconsciente chega a uma atmosfera sufocante de subjetividade egocêntrica, ficando neste beco sem saída à mercê do ataque de todos os animais ferozes abrigados na caverna do submundo anímico.” (Jung, p. 28)

O inconsciente, seja o individual, seja o coletivo, é uma porção da psique que o ser humano guarda escondida, esquecida e com a qual trava uma eterna luta de memória e esquecimento, luta esta que o acompanha desde tempos imemoriais. A própria palavra pessoa, de persona, significa esta máscara que colocamos no rosto, a mesma máscara do ator, que esconde a verdade, ou que mostra apenas uma meia verdade.

Neste ponto merece mencionarmos a lição de Willis Santiago Guerra Filho, ancorado em Lacan:

"Certa feita disse Jacques Lacan, em um de seus Seminários, 36 “o que vem lá do começo tem um nome: é o mito". Myeîn, em grego antigo, significava iniciar - e também calar, sobre o que se transmitia na iniciação. No mito, então, mascara-se a verdade. Mas ela está lá, só que mascarada, enfeitada. 
Talvez isso seja preciso por não ser tão bela e agradável olhar para ela; por não suportarmos vê-la diretamente, sem anteparos, assim como não suportamos olhar de frente, por muito tempo, o sol - ou a morte.” (p. 34)

E continua:

\begin{abstract}
“Aqui, vale observar que não há uma só explicação para a origem etimológica da palavra "símbolo" - como, aliás, ocorre com frequência, em etimologia -, mas penso que aí, mesmo quando fantasiosa uma explicação dada, ela não perde seu valor como expressão do imaginário - e a explicação real, do real, de qualquer forma, é impossível de ser dada, pois ele se define - em Lacan -, precisamente, como o que nos escapa. Para nós, nesse contexto, mito é uma fantasia estruturante do sujeito, uma verdade, que, como toda verdade, "tem uma estrutura de ficção", e "só pode ser concebida se enunciada em um semidizer". (Guerra Filho, p. 34)
\end{abstract}

Este último trecho é espetacular: "a explicação do real é impossível de ser dada, pois ele se define como o que nos escapa". Toda verdade tem, assim, uma estrutura de ficção, é um semi-dizer.

O inconsciente é a nossa meia verdade, é a sombra que não queremos ver. Por mais que o homem busque afastar esta porção esquecida, o inconsciente acaba vencendo esta batalha e o esquecido é lembrado.

Como muito bem conclui Jung, "na verdade, nunca nos libertaremos legitimamente do fundamento arquetípico, a não ser que estejamos dispostos a pagar o preço de uma neurose, da mesma forma que não nos livraremos de nosso corpo e de seus órgãos sem cometer suicídio.” (Jung, p. 158/159) 
Não se pode, na lição da psicanálise junguiana, afastar o passado, desligá-lo, sob pena de morte do homem. Este é o ensinamento que trazemos para o direito, para o debate do esquecimento: há fundamento para o esquecimento? Eventual norma é benéfica para o homem? Em quais situações? A resposta há que ser negativa, conclusão a que chegamos a partir da leitura de Jung:

"Se esta conexão não ocorrer cria-se uma consciência desenraizada, que não se orienta pelo passado, uma consciência que sucumbe desamparada a todas as sugestões, tornando-se suscetível praticamente a toda epidemia psíquica. Com a perda do passado, tornado insignificante, desvalorizado, impossível de recuperar seu valor, também se perde o salvador, pois este é o próprio insignificante, ou dele surge." (p. 159)

Possui o arquétipo uma função de equilíbrio com a parte consciente da psique, além de assumir importante função com relação ao futuro: "não representa apenas algo que existiu no passado longínquo, mas também algo presente; não é somente um vestígio, mas um sistema que funciona ainda, destinado a compensar ou corrigir as unilateralidades ou extravagâncias inevitáveis da consciência." (Jung, p. 164) Aludindo ao "motivo da criança” Jung leciona que significa em regra geral uma antecipação de desenvolvimentos futuros, mesmo que pareça tratar-se à primeira vista de uma configuração retrospectiva. A vida é um fluxo, um fluir para o futuro e não um dique que estanca e faz refluir." (Jung, p. 166).

\section{Freud, Lacan, a primazia do inconsciente, recalque e esquecimento}

A concepção corriqueira e primeira que teríamos de inconsciente o relacionaria a algo esquecido, reprimido, algo que se nos parece de diminuta importância, secundário. O consciente, ao contrário, seria o lado principal da psique, que governaria a vida humana. 
$\mathrm{O}$ consciente estaria, assim, ligado ao normal, enquanto o inconsciente estaria vinculado às patologias, às anormalidades da vida humana.

Freud, o entanto, dá ao inconsciente uma posição ímpar, ligando-o às ações normais da existência. Como muito pondera Coutinho Jorge "nenhuma de nossas ações, escolhas, tendências, desejos escapa à ação do inconsciente, o que faz com que a fronteira tão rígida entre normal e patológico, construída outrora pelo saber psiquiátrico, se torne algo inexistente.” (2005, p. 11). E conclui o mesmo autor, citando Freud, que .. não há nada no psíquico que seja produto de um livre arbítrio, que não obedeça a um determinismo... (p. 11).

Lacan, objeto de profundo estudo de Coutinho Jorge, chega a afirmar que "o inconsciente é a verdadeira doença mental do homem". Já Freud certa feita escreveu a Groddeck que "o inconsciente é certamente o verdadeiro intermediário entre o somático e o psíquico, talvez seja o missing link tão procurado." (Coutinho Jorge, 2005, p. 12)

Este é o motivo de nossas reflexões. Segundo pensamos, a psicanálise está de tal forma imbricada com o direito pois pode trazer contribuições para a reflexão acerca das decisões na criação das novas regras jurídicas, bem como pode nos auxiliar a entender muito acerca das decisões judiciais. A contribuição ganha corpo ainda maior diante do tema eleito para debate, o de um suposto direito de ser esquecido.

Importante destacar as palavras de Nietzsche, ao aludir ao sonho para afirmar que no sonho "prossegue atuado uma antiquíssima relíquia do humano que já não se pode alcançar por um caminho direto". (Coutinho Jorge, 2005, p. 12)

O sonho é uma das formas de se compreender o inconsciente. Freud quer crer que "o sonho e neurose conservaram para nós da antiguidade da alma mais do que poderíamos supor, de sorte que a psicanálise pode reivindicar para si um lugar de destaque entre as ciências que se esforçam por 
reconstruir as fases mais antigas e obscuras dos primórdios da humanidade.” (Coutinho Jorge, 2005, p. 12)

O conceito de inconsciente de Freud é desenvolvido posteriormente por Lacan, que trabalha a ideia de real-simbólico-imaginário, partindo da ideia de inconsciente estruturado como linguagem.

Para Freud, o inconsciente desfigurou um verdadeiro golpe sobre o homem, ao assentar que é ele o ponto principal, subvertendo uma lógica até então existente e que governava a existência humana.

Um primeiro conceito chave para a psicanálise é o conceito de pulsão, diferenciando-o de instinto.

Segundo entende Freud, no ser-humano a sexualidade é diversa dos animais, que agem por instinto. No homem, ao contrário, a sexualidade se manifesta sob uma aparência errática e subdita a uma lógica diferente daquela que rege os instintos animais." (Coutinho Jorge, 2005, p. 21). Com base no estudo da sexualidade, Freud entende que sua estrutura é, essencialmente, traumática, sempre.

A partir do conceito de recalque orgânico, Freud compreende a sexualidade como pulsional e não instintual.

Recalque não se confunde com repressão. Enquanto a repressão é devida a um fator externo, o recalque é um mecanismo estrutural e estruturante. Ele pode ser definido como a "operação pela qual o indivíduo procura repelir ou manter no inconsciente representações ligadas a uma pulsão". (Coutinho Jorge, 2005, p. 23) 
O recalque não é assim um simples mecanismo de defesa, mas um mecanismo constitutivo do inconsciente. $\mathrm{O}$ recalque atua de forma constante, pois a pulsão, sua força contrária, também atua constantemente. O recalque é um processo contínuo.

Freud, então, desenvolve o conceito de recalque originário, constitutivo do inconsciente. A pulsão não se restringe à sexual. Há outras formas de pulsão, como a pulsão de vida e a pulsão de morte.

Segundo pontifica Freud, citado por Coutinho Jorge (2005, p. 49), “uma pulsão nos aparecerá como um conceito fronteiriço entre o psíquico e o somático, como um representante psíquico dos estímulos que provém do interior do corpo e alcançam a mente, como uma medida de exigência de trabalho que é imposta à mente em consequência de sua ligação com o corporal."

Mas é com o conceito de pulsão de morte que Freud irá destacar seus caracteres principais. Primeiramente, seu caráter conservador, restitutivo, e por outro lado, seu aspecto repetitivo." (Coutinho Jorge, 2005, p. 61).

Esta repetição é posteriormente tematizada por Lacan em duas vertentes, o autômaton e a tique, a articulação interna e indissociável para o sujeito falante entre o simbólico e o real, entre o inconsciente e a pulsão.

Recalque não se confunde com esquecimento. Neste último, "a porta entre consciente e préconsciente, tal como numa sala ligada a uma antessala, mantém-se aberta e pode ser franqueada a qualquer momento"... no recalque, a passagem do consciente para o inconsciente acha-se hermeticamente fechada e a chave não está na fechadura, devendo ser procurada!" (Coutinho Jorge, 2010, p. 42) 
Estabelecidos estes conceitos iniciais Lacan desenvolve a teoria de Freud sobre o inconsciente, ligando-o ao tema da linguagem.

Importante consignar que inconsciente não é sinônimo de não consciente. A psicanálise nos ensina, ademais, que o inconsciente não é algo secundário, somático, destituído de importância. Pelo contrário, não há nada que façamos que nos escapa ao inconsciente. É ele o verdadeiro motor das condutas humanas, e não o consciente!

$\mathrm{O}$ inconsciente é um saber que não se sabe, um saber que governa as condutas humanas. $\mathrm{O}$ acesso a este saber é realizado através do estudo dos sonhos, dos chistes, das manifestações neuróticas.

O termo inconsciente é um termo falho, deficiente, que inicialmente nos dá ideia de oposto ao consciente, como algo secundário, obscuro.

Melhor é o termo alemão utilizado para designá-lo: Unberwusste, que significa literalmente insabível (Coutinho Jorge, 2005, p. 66), para aludir ao fato de o consciente ser um saber que se sabe e o inconsciente um saber que não se sabe.

Lacan entende que o inconsciente preenche o vazio da falta de instinto inerente ao homem. Na lição ainda de Coutinho Jorge (2005, p. 67), citando Lacan:

“... o ser humano manifestamente não tem nenhum saber instintual... só há o inconsciente para dar corpo ao instinto ... o inconsciente, nós imaginamos que é alguma coisa como um instinto, mas isto não é verdade. O instinto nos falta inteiramente, e a maneira pela qual reagimos está ligada não a um instinto, mas a um certo saber veiculado não tanto por palavras quanto pelo que eu chamo de significantes". 
Consciente e inconsciente são conceitos básicos trabalhados pela psicanálise. O inconsciente ocupa posição de grande importância, consistindo num poço de conhecimentos ainda não explorados, verdadeiro saber que não se sabe e que governa os passos do homem. O direito, trabalhando com determinações, especialmente no atinente à memória, lembrança, esquecimento, certamente objetiva atingir o lado consciente dos indivíduos, mas não possuirá eficácia alguma a nível inconsciente, onde os fatos e as memórias permanecerão latentes e vivas na civilização.

\section{CONCLUSÕES}

O direito ao esquecimento consiste na possibilidade de impedir a divulgação de fatos desabonadores ou criminosos de uma pessoa, fundado na ressocialização ou mesmo no decurso de um lapso temporal dos fatos ocorridos. Este decurso do prazo funcionaria como estabilizador da situação jurídica, impedindo que os fatos deletérios fossem revolvidos.

Buscamos na psicanálise fundamentos para o debate do tema do esquecimento. Esta ciência trabalha com diversas dualidades muito semelhantes à memória/esquecimento, como o consciente/inconsciente, normal/patológico, pulsão/recalque, e os conceitos de real/simbólico/imaginário.

Pudemos verificar que a psicanálise passa a ver o inconsciente, antes renegado ao esquecimento, à obscuridade, numa posição de primazia, como sendo um "saber que não se sabe", como verdadeiro governador das condutas humanas. Podemos concluir que apagar o passado não é e nunca será solução, pois por mais que pensemos nesta possibilidade ela mostrar-se-á impraticável, pois a existência pretérita do homem está indelevelmente inscrita e o acompanhará por toda sua existência, no consciente e no inconsciente. 


\section{REFERÊNCIAS BIBLIOGRÁFICAS:}

COUTINHO JORGE, Marco Antonio. Fundamentos da Psicanálise, de Freud a Lacan, volume 1, As bases conceituais, $2^{\mathrm{a}}$ edição, Rio de Janeiro-RJ: Zahar, 2005.

COUTINHO JORGE, Marco Antonio. Fundamentos da Psicanálise, de Freud a Lacan, volume 2, A Clínica da Fantasia, 2ª edição, Rio de Janeiro-RJ: Zahar, 2010.

FREUD, Sigmund. Totem e Tabu, Penguin \& Companhia das Letras, tradução de Paulo César de Souza, $1^{a}$ edição, São Paulo, Penguin \& Companhia das Letras, 2013.

JUNG, Carl Gustav, Os arquétipos e o inconsciente coletivo. $11^{a}$ edição, tradução de Maria Luiza Appy, Dora Mariana R Ferreira da Silva, Petrópolis-RJ: Vozes, 2014.

GUERRA FILHO, Willis Santiago, O conhecimento imaginário do direito. Curitiba: Editora Prismas, 2016. 